\title{
Effect of pioglitazone on the calcification of rat vascular smooth muscle cells through the downregulation of the Wnt/ $\beta$-catenin signaling pathway
}

\author{
MIN GAO $^{1,2}$, TIANLEI CHEN ${ }^{1,3}$, LIN WU $^{1}$, XIUFEN ZHAO $^{1}$, HUIJUAN MAO $^{1}$ and CHANGYING XING ${ }^{1}$ \\ ${ }^{1}$ Department of Nephrology, Jiangsu Province Hospital, The First Affiliated Hospital of Nanjing Medical University, \\ Nanjing, Jiangsu 210029; ${ }^{2}$ Department of Nephrology, Wujin People's Hospital, Changzhou, Jiangsu 213002; \\ ${ }^{3}$ Department of Nephrology, Changzhou First People's Hospital, Changzhou, Jiangsu 213003, P.R. China
}

Received November 12, 2016; Accepted July 3, 2017

DOI: $10.3892 / \mathrm{mmr} .2017 .7308$

\begin{abstract}
The aim of the present study was to investigate the effect and possible mechanism of pioglitazone (PIO) on the calcification of rat vascular smooth muscle cells (VSMCs) in vitro. $\beta$-glycerophosphate $(\beta$-GP; $10 \mathrm{mmol} / \mathrm{l})$ was used to induce calcification of VSMCs treated with a range of concentrations $(5,10,15$ and $20 \mu \mathrm{mol} / \mathrm{l})$ of PIO for 12 days. Calcium deposits were revealed by Alizarin red staining. Extracellular calcium content was detected using a calcium assay kit. Western blotting was used to measure the expression of $\alpha$-smooth muscle actin $(\alpha$-SMA), runt-related transcription factor 2 (Runx2), bone morphogenetic protein-2 (BMP2), $\beta$-catenin, glycogen synthase kinase- $3 \beta$ (GSK-3 $\beta$ ), phosphorylated (p)-GSK-3 $\beta$ and cyclin-D1. A total of $10 \mathrm{mmol} / \mathrm{l} \beta$-GP, $20 \mu \mathrm{mol} / \mathrm{l} \mathrm{PIO}$ and $20 \mu \mathrm{mol} / 1$ peroxisome proliferator-activated receptor $\gamma$ (PPAR $\gamma$ ) antagonist GW9662, was added to the cell culture media. The changes of the above indexes were observed. The calcium content in the calcification group, treated with high phosphorus, increased significantly compared with the controls $(\mathrm{P}<0.05)$ and all different concentrations of PIO reduced extracellular calcium content $(\mathrm{P}<0.05)$. Alizarin red staining was positive in calcified VSMCs and PIO (20 $\mu \mathrm{mol} / \mathrm{l})$ intervention group was almost negative. The expressions of Runx $2, \beta$-catenin, p-GSK-3 $\beta$, BMP2 and cyclin-D1 increased significantly in the calcification group, and treatment with $20 \mu \mathrm{mol} / \mathrm{l}$ PIO downregulated the expression of all the above proteins, while upregulating the expression of $\alpha$-SMA. The PPAR $\gamma$ antagonist GW9662 could partly inhibit the effect
\end{abstract}

Correspondence to: Professor Huijuan Mao, Department of Nephrology, Jiangsu Province Hospital, The First Affiliated Hospital of Nanjing Medical University, 300 Guangzhou Road, Nanjing, Jiansu 210029, P.R. China

E-mail: maohuijuan72@hotmail.com

Key words: peroxisome proliferator-activated receptor $\gamma$, pioglitazone, $\beta$-glycerophosphate, vascular smooth muscle cells, Wnt/ $\beta$-catenin signaling pathway, calcification of PIO on calcified VSMCs. The results of the present study indicated that PIO can alleviate the calcification of rat aortic VSMCs induced by $\beta$-GP via inhibiting the activity of the $\mathrm{Wnt} / \beta$-catenin signaling pathway.

\section{Introduction}

A number of studies have demonstrated that calcium and phosphorus metabolism disorders that promote vascular calcification (VC) and mediate the development of cardiovascular disease, affect the survival of patients with chronic kidney disease (CKD) (1-3). VC used to be considered a passive process of deposition of calcium in the extracellular matrix; however, more studies $(4,5)$ have demonstrated that $\mathrm{VC}$ is a similar process to bone formation, which is regulated by various factors and its central point is the change of the phenotype of vascular smooth muscle cells (VSMCs) to osteogenic cells. High phosphorus (HP) is one of the most important risk factors and contributors of $\mathrm{VC}$ in CKD condition (6).

$\mathrm{VC}$ of media, also known as Monckeberg's calcification, is the characteristic VC that appears in patients with CKD, which results in hardening of the whole vasculature, decreased blood vessel elasticity and hemodynamic alterations (7). Furthermore, patients with CKD frequently present with calcified heart valves and calciphylaxis (8).

Peroxisome proliferator-activated receptor $\gamma(\operatorname{PPAR} \gamma)$ is a nuclear receptor, which is involved in fatty acid and energy metabolism. A PPAR $\gamma$ agonist is a type of insulin-sensitizing agent and the range of clinical uses has increased in recent years. The activation of PPAR $\gamma$ can regulate metabolism, reduce inflammation, affect the balance of immune cells, inhibit apoptosis, oxidative stress and improve endothelial cell function (9). PPAR $\gamma$ agonists have many potential therapeutic effects, including regulation of bone remodeling, due to their pleiotropic activity (10). A previous study identified that upregulation of the activity of PPAR $\gamma$ receptor could reduce VC induced by diabetes (11). Pioglitazone (PIO) is a novel generation of PPAR $\gamma$ agonist. The present study aimed to investigate whether PIO could alleviate calcification of VSMCs induced by HP and to elucidate its possible mechanism. 


\section{Materials and methods}

Reagents. PIO and the PPAR $\gamma$ inhibitor GW9662 were bought from Selleck Chemicals (Houston, TX, USA). The calcium deposition assay (Calcium Assay kit) was from Nanjing Jiancheng Bioengineering Institute (Nanjing, China). $\beta$-glycerophosphate $(\beta$-GP) was purchased from Sigma-Aldrich (Merck KGaA, Darmstadt, Germany). Antibodies for $\alpha$-smooth muscle actin ( $\alpha$-SMA; cat. no. 14395-1-AP), runt-related transcription factor 2 (Runx2; cat. no. 20700-1-AP), and GAPDH (cat. no. 10494-1-AP) were from Wuhan Sanying Biotechnology (Wuhan, China). Antibodies for bone morphogenetic protein-2 (BMP2; cat.

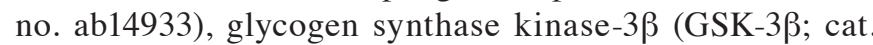
no. ab32391), phosphorylated (p)-GSK-3 $\beta$ (cat. no. ab30619) and $\beta$-catenin (cat. no. ab16051) were from Abcam (Cambridge, UK). The antibody against cyclin D1 (cat. no. 2922) was purchased from Cell Signaling Technology, Inc. (Danvers, MA, USA). Anti-histone deacetylase (HDAC1; cat. no. PA1-860) was from Thermo Fisher Scientific, Inc., (Waltham, MA, USA). The horseradish peroxidase-conjugated secondary antibody (cat.no. ZB-2301) was from OriGene Technologies, Inc. (Beijing, China).

Cell culture. The rat VSMC A7r5 cell line was purchased from the American Type Culture Collection (Manassas, VA, USA). The VSMCs were cultured serially in Dulbecco's modified Eagle medium (DMEM; Gibco, Thermo Fisher Scientific, Inc.) containing $10 \%$ fetal bovine serum (FBS; Hyclone; GE Healthcare Life Sciences, Logan, UT, USA), $100 \mathrm{U} / \mathrm{ml}$ penicillin and $0.1 \mathrm{mg} / \mathrm{ml}$ streptomycin. Cultures were maintained at $37^{\circ} \mathrm{C}$ in a humidified atmosphere of $5 \% \mathrm{CO}_{2}$ and $95 \%$ air. The VSMCs were divided into 5 groups: i) Control, which was cultured in ordinary medium; ii) control + dimethylsuphoxide (DMSO; $25 \mathrm{mg} / \mathrm{ml}$ ); iii) $\mathrm{HP}$, which was cultured in media with $10 \mathrm{mM} \beta-\mathrm{GP}$; iv) $\mathrm{HP}+$ DMSO (25 mg/ml); v) HP + PIO, HP group with 5, 10, 15 or with $20 \mu \mathrm{M}$ PIO was dissolved in DMSO respectively; and vi) $\mathrm{HP}+\mathrm{PIO}+\mathrm{GW} 9662$, culture medium containing $10 \mathrm{mM} \beta$-GP, $20 \mu \mathrm{M}$ PIO and $20 \mu \mathrm{M}$ GW9662. When VSMCs were at $70-80 \%$ confluence in ordinary media, the cells were switched to the calcification medium, i.e., DMEM growth medium containing $10 \mathrm{mM} \beta-\mathrm{GP}, 50 \mu \mathrm{g} / \mathrm{ml}$ vitamin $\mathrm{C}$ and $1 \times 10^{-7} \mathrm{~mol} / \mathrm{l}$ insulin (Sigma-Aldrich; Merck KGaA) for 12 days. The medium was replaced every 3 days.

Detection of VSMC calcification. Following 12 days of the VSMCs being cultured, the deposition of calcium in cells was detected using 2\% Alizarin red staining for $2 \mathrm{~min}$ at $4{ }^{\circ} \mathrm{C}$. To determine the calcium concentrations in the VSMCs, cells were decalcified with $0.6 \mathrm{M} \mathrm{HCl}$ for $24 \mathrm{~h}$ at $37^{\circ} \mathrm{C}$. Calcium content of culture supernatant was tested by the o-cresolphthalein complexone and then normalized to protein content.

Western blot analysis. Cells were lysed in lysis buffer, containing $25 \mathrm{mM}$ Tris- $\mathrm{HCl}(\mathrm{pH} 7.5), 150 \mathrm{mM} \mathrm{NaCl}, 1 \%$ Triton X-100, 5 mM EDTA, 5 mM EGTA, $10 \mathrm{mM}$ aprotinin, $10 \mathrm{mM}$ leupeptin and $100 \mathrm{mM}$ phenylmethylfluoride (Nanjing KeyGen Biotech Co., Ltd., Nanjing, China). Protein concentration was determined using a bicinchoninic acid protein assay (Nanjing KeyGen Biotech Co., Ltd.). Equal amounts of extracted protein samples $(60 \mu \mathrm{g})$ were separated by $10 \%$ SDS-PAGE and transferred onto polyvinylidene fluoride membranes (EMD Millipore, Billerica, MA, USA). The membranes were blocked with $5 \%$ non-fat dry milk in TBS $0.02 \%$ Tween-20 (TBST) for $2 \mathrm{~h}$ at room temperature and then incubated overnight at $4^{\circ} \mathrm{C}$ with the following primary antibodies: Anti- $\alpha-S M A$, anti-BMP2, anti-GSK-3 $\beta$, anti-p-GSK-3 $\beta$, anti- $\beta$-catenin, anti-cyclin D1, anti-HDAC (dilution, 1:1,000), anti-Runx2 (dilution, 1:500), anti- $\beta$-catenin (dilution, 1:2,000) and anti-GAPDH (dilution, 1:5,000). The membranes were then incubated for $1 \mathrm{~h}$ at room temperature under agitation with the secondary antibody (dilution, 1:8,000). The membranes were washed 3 times for 10 min each with TBST at room temperature, and protein bands were visualized with enhanced chemiluminescence (Thermo Fisher Scientific, Inc.) on a Bio-Rad imaging system (Bio-Rad Laboratories, Inc., Hercules, CA, USA). Blots were semi-quantified by densitometry using Image Lab software version 3.0 (Bio-Rad Laboratories, Inc.). All experiments were repeated at least three times.

Statistical analysis. Statistical analyses were performed using SPSS software version 19.0 (SPSS, Inc., Chicago, IL, USA). All quantitative data were presented as the mean \pm standard deviation. Multiple comparisons were evaluated using one-way analysis of variance and significant differences between two groups were analyzed using the Student-Newman-Keuls test. $\mathrm{P}<0.05$ was considered to indicate a statistically significant difference.

\section{Results}

Calcification of VSMCs. Following culture for 12 days, Alizarin red staining demonstrated that the cell matrix was not colored and the reaction of calcified nodules was negative in the control group, while Alizarin red staining verified the formation of mineralized nodules in the HP group. DMSO itself had no effect on calcification. Compared with the HP group, the extent of calcification of the extracellular matrix in $\mathrm{HP}+5 \mu \mathrm{M}$ $\mathrm{PIO}$ group and $\mathrm{HP}+10 \mu \mathrm{M}$ PIO group was less than that of HP group. The HP $+15 \mu \mathrm{M}$ PIO group and $\mathrm{HP}+20 \mu \mathrm{M}$ PIO group almost demonstrated no calcium deposition (Fig. 1). Following 12 days of culture, the calcium content of the extracellular matrix (mmol/g) in HP group $(1.7509 \pm 0.0364)$ was increased compared with the control group (1.3209 \pm 0.19567$)$. Following treatment with 5, 10, 15 and $20 \mu \mathrm{M}$ PIO, the calcium content of the extracellular matrix was $1.2791 \pm 0.0694,1.3873 \pm 0.0996$, $1.2660 \pm 0.0828$ and $1.3857 \pm 0.0634$ respectively, which were all decreased compared with the HP group. The four different concentrations of $\mathrm{PIO}$ all significantly reduced the calcification of rat VSMCs $(\mathrm{P}<0.01$; Fig. 2A). The calcium content increased significantly in the group treated with HP + PIO + GW96620 compared with the control $(\mathrm{P}<0.01$; Fig. $2 \mathrm{~B})$.

Expression levels of $\alpha-S M A, B M P 2$ and Runx2. Compared with the control group, the protein level of $\alpha$-SMA in the HP group was significantly reduced. Compared with the HP group, the expression of $\alpha$-SMA in the group treated with $20 \mu \mathrm{M}$ 
A

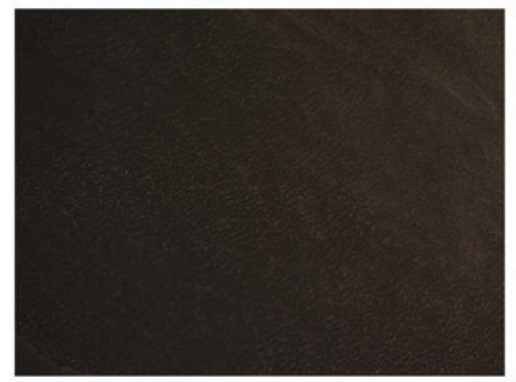

C

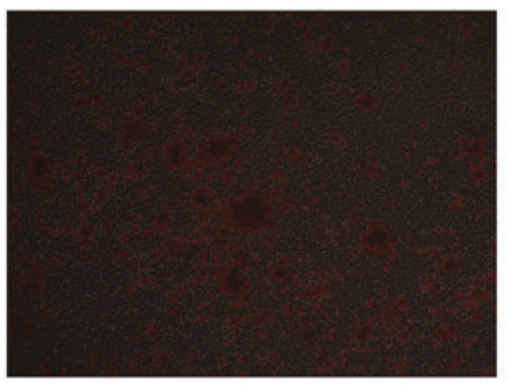

E

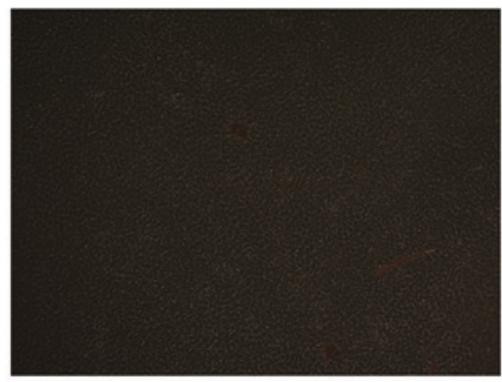

B

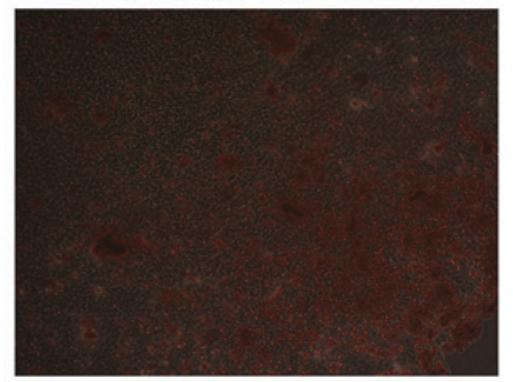

D

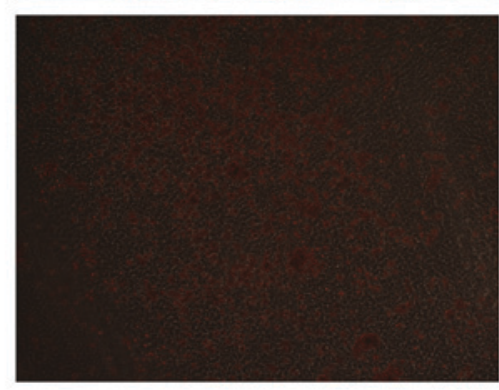

F

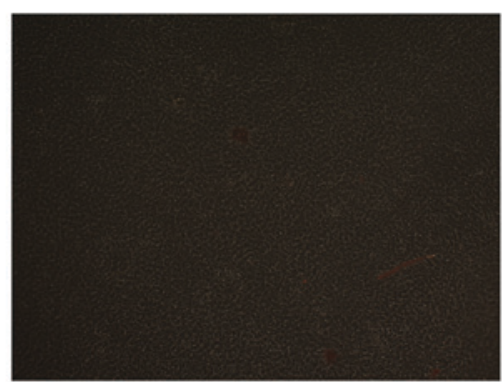

Figure 1. Alizarin red (2\%; pH 4.2) staining of cells (magnification, $\mathrm{x} 4$ ). (A) Control group, (B) HP (10 mM $\beta$-glycerophosphate), (C) HP $+5 \mu \mathrm{M}$ PIO, (D) HP $+10 \mu \mathrm{M}$ PIO, (E) HP $+15 \mu \mathrm{M}$ PIO and (F) HP $+20 \mu \mathrm{M}$ PIO. PIO was dissolved in DMSO. The results demonstrated DMSO itself exhibited no effect on calcification. HP, high phosphate; DMSO, dimethylsulphoxide; PIO, pioglitazone.

A

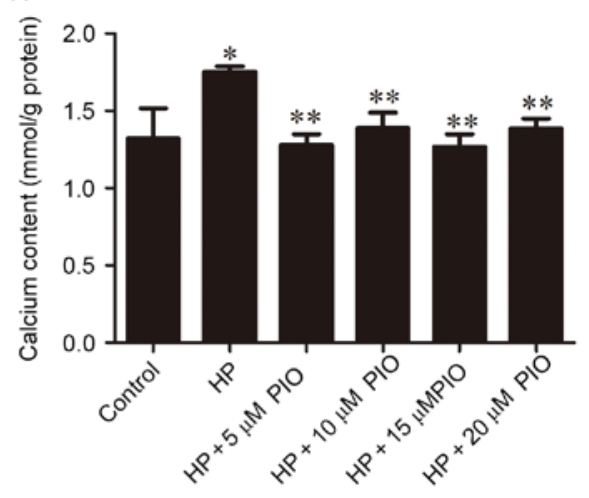

B

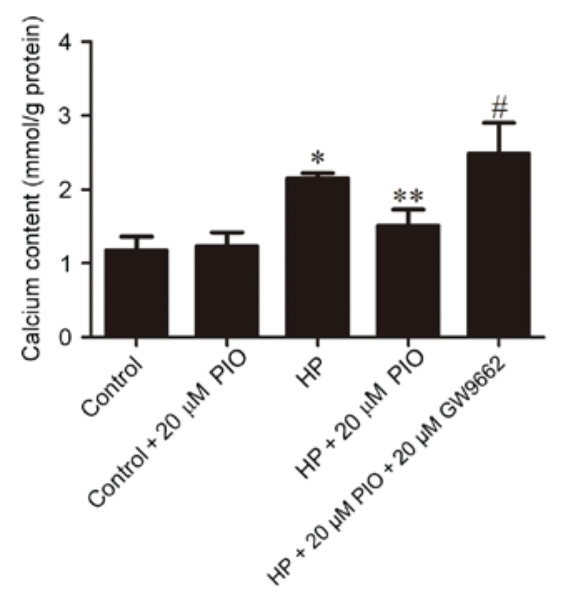

Figure 2. Analysis of the calcium content of the extracellular matrix. (A) Rat VSMCs treated with: Control; HP (10 mM $\beta$-GP); HP + $5 \mu \mathrm{mol} / \mathrm{l} \mathrm{PIO}$; $\mathrm{HP}+10 \mu \mathrm{mol} / 1 \mathrm{PIO} ; \mathrm{HP}+15 \mu \mathrm{mol} / 1 \mathrm{PIO}$; and HP $+20 \mu \mathrm{mol} / 1$ PIO. (B) Rat VSMCs treated with: Control; control + $20 \mu \mathrm{mol} / 1 \mathrm{PIO}$; HP: (10 mM $\beta$-GP); $\mathrm{HP}+20 \mu \mathrm{mol} / 1 \mathrm{PIO}$; and $\mathrm{HP}+20 \mu \mathrm{mol} / 1 \mathrm{PIO}+20 \mu \mathrm{mol} / 1 \mathrm{GW} 9662 .{ }^{*} \mathrm{P}<0.01 \mathrm{vs}$. control group; ${ }^{* *} \mathrm{P}<0.01 \mathrm{vs}$. HP group; ${ }^{\sharp} \mathrm{P}<0.01 \mathrm{vs}$. HP $+20 \mu \mathrm{mol} / 1 \mathrm{PIO}$ group. HP, high phosphate; PIO, pioglitazone; $\beta$-GP, $\beta$-glycerophosphate; VSMCs, vascular smooth muscle cells.

PIO increased (Fig. 3A). The expression levels of BMP2 and Runx 2 in the HP group were increased compared with the control group. Compared with the HP group, levels of BMP2 and Runx 2 in the group treated with $20 \mu \mathrm{M}$ PIO decreased relatively (Fig. 3B and C).
PIO and the Wnt/ $\beta$-catenin signaling pathway. To investigate whether PIO reduced VC via the $\mathrm{Wnt} / \beta$-catenin signaling pathway, the expression of the associated proteins $\beta$-catenin, p-GSK-3 $\beta$, GSK-3 $\beta$ and cyclin-D1 was observed. The levels of $\beta$-catenin, $p-G S K-3 \beta / G S K-3 \beta$ and cyclin-D1 increased in the 
A
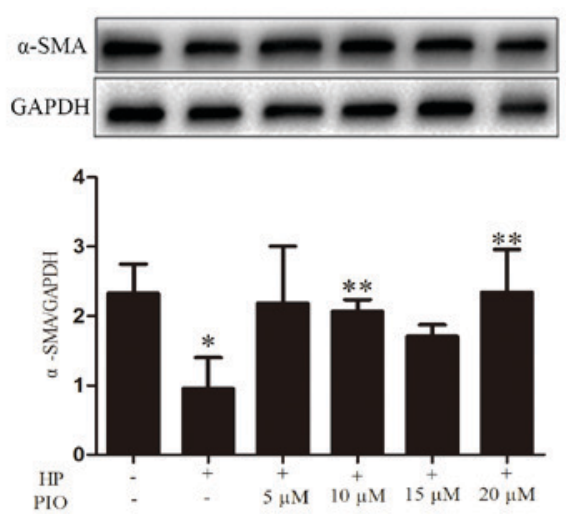

C
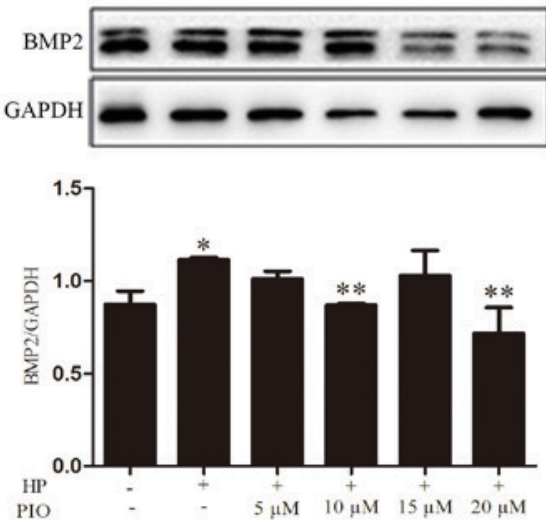

B Runx2 $\beta$-Catenin GAPDH
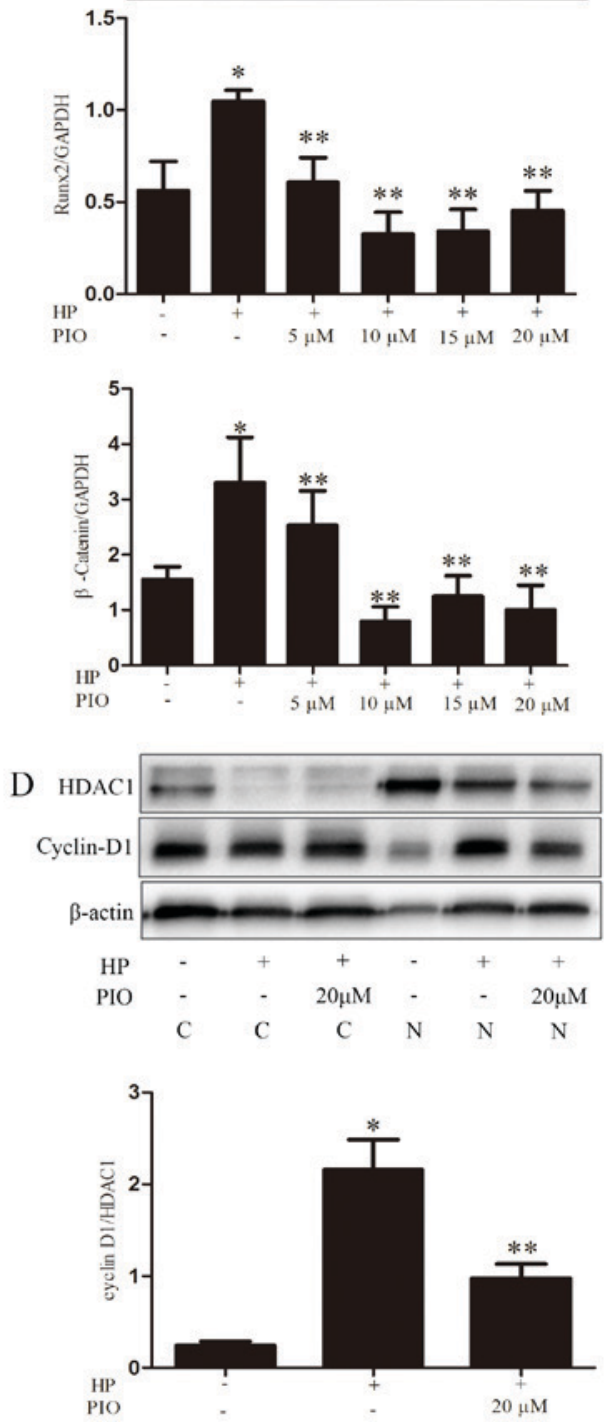

Figure 3. $\alpha$-SMA, Runx2 and BMP2 expression were analyzed by western blotting using GAPDH as the loading control. The quantification of the expression levels of (A) $\alpha$-SMA, (B) Runx 2 and $\beta$-catenin, (C) BMP2, and (D) cyclin D1/HDAC1 were represented as the mean \pm standard error (n=5/group) for each group in its respective column. ${ }^{*} \mathrm{P}<0.05$ vs. control group; ${ }^{* *} \mathrm{P}<0.05$ vs. HP group. HP, high phosphate; $\alpha$-SMA, $\alpha$-smooth muscle actin; Runx 2 , runt-related transcription factor 2; BMP2, bone morphogenetic protein-2; PIO, pioglitazone; HDAC1, histone deacetylase 1; C, cytoplasmic; N, nuclear.

HP group compared with the controls; while the expressions of the above proteins were decreased in the $\mathrm{HP}+20 \mu \mathrm{M}$ PIO group compared with those of the HP group (Figs. 3 and 4).

Effect of PPAR $\gamma$ inhibitor GW9662 on calcification. The calcium content of HP + PIO + GW9662 group increased compared with $20 \mu \mathrm{M}$ PIO intervention group (Fig. 2B). The

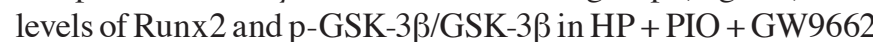
group were significantly increased compared with those of $20 \mu \mathrm{M}$ PIO intervention group $(\mathrm{P}<0.01$; Fig. 4).

\section{Discussion}

VC in patients with CKD is common and considered to be associated with an increased risk of mortality (12). The progression of calcification in patients with CKD is linked to the serum phosphorus level, phosphate is an integral part of hydroxyapatite and also an important signaling cascade trigger factor in VC (13). The present study demonstrated that $10 \mathrm{mM} \beta$-GP induced calcification of rat VSMCs: Alizarin red staining revealed calcified nodules, and the calcium content of extracellular matrix increased. In addition, compared with control group, the expression of $\alpha$-SMA decreased, while BMP2 and Runx2 increased, consistent with previous study results $(14,15)$.

Previous studies suggested that PPAR $\gamma$ was an important regulatory factor in bone remodeling, which served the role of molecular switch for the differentiation of mesenchymal stem cells (MSCs) into adipocyte and osteoblasts. Increasing the expression of PPAR $\gamma$ and enhancing its activity, may 

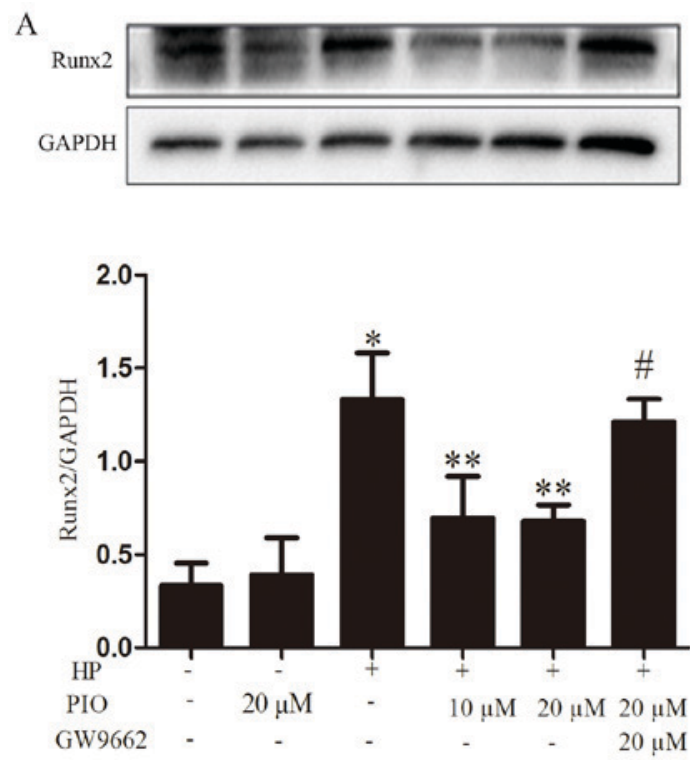

B

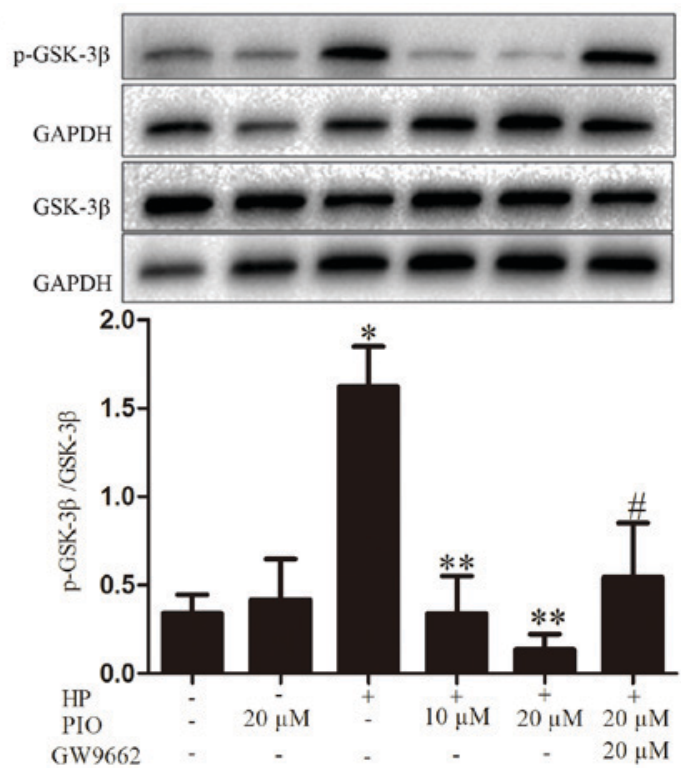

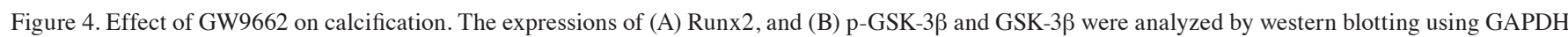
as the loading control. The quantification of the expression levels of Runx2, p-GSK-3 $\beta / G S K-3 \beta$ were represented as the mean \pm standard error ( $\mathrm{n}=5 / \mathrm{group}$ ) for each group in its respective column. ${ }^{*} \mathrm{P}<0.001$ vs. control group; ${ }^{* *} \mathrm{P}<0.01$ vs. HP group; ${ }^{*} \mathrm{P}<0.05$ vs. HP $+20 \mu \mathrm{mol} / 1 \mathrm{PIO}+20 \mu \mathrm{mol} / 1 \mathrm{GW} 9662$. Runx2,

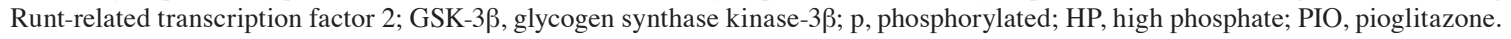

inhibit the differentiation of MSCs to the osteogenic cells (10). Embryonic stem cells with a homozygous PPAR $\gamma$ defection cannot differentiate into fat cells; however, can spontaneously differentiate into osteoblasts (16). A number of studies confirmed that PPAR $\gamma$ could reduce VC induced by high fat and glucose $(17,18)$. The aim of the present study was to investigate whether regulating the activity of PPAR $\gamma$ could reduce the VC induced by $\mathrm{HP}$ levels. The results demonstrated that PIO intervention could decrease the calcium content of extracellular matrix to the level where Alizarin red staining was negative. The expression level of $\alpha$-SMA increased while the levels of BMP2 and Runx2 decreased when treated with PIO. These results demonstrated that PIO could reduce the calcification of rats VSMCs induced by HP and inhibit the differentiation of VSMCs into osteoblast-like cells.

Wnt signaling pathway has a key role in bone formation. Low density lipoprotein receptor (LRP)-related protein 5 is a co-receptor of Wnt signaling pathways (19). Mouse models of the activation of the Wnt signaling pathways demonstrate that it can increase bone mass (20). Further studies demonstrated that inhibiting or reducing the antagonists of the Wnt signaling pathways, including secreted frizzled-related protein 1 (sfrp1), adenomatosus polyposis coli protein and dickkopf-related protein 1 (Dkk1) can increase the trabecular bone (20-24); while overexpression of antagonists including Dkk1 may reduce bone mineral density (24-26). The key process of VC is the phenotype transformation from VSMCs to osteoblast $(4,5)$. The aim of the present study was to investigate whether there was an association between the Wnt signaling pathway and VC.

The canonical Wnt signaling pathways are also known as the Wnt $/ \beta$-catenin signaling pathways. When Wnt ligands bind to frp, it can interact with disheveled, a cytoplasmic protein that acts upstream of $\beta$-catenin and GSK-3 $\beta$. Then GSK-3 $\beta$ becomes phosphorylated and the complex dissociates. $\beta$-catenin cannot be degraded in the cytoplasm and therefore steadily accumulates and then enters the nucleus, combining with transcription factor-4/lymphoid enhancer-binding factor 1 (TCF/LEF, respectively) and activates the expression of Wnt signaling pathway targeted genes, and participates in a variety of physiological mechanisms (27). The downstream targeted genes of the canonical Wnt signaling pathways includes several associated with cell proliferation, such as protooncogene c-myc and cyclin D1 (28). The expression level of cyclin D1 can reflect the activity of the Wnt signaling pathway. Woldt et al (17) demonstrated that a PPAR $\gamma$ agonist could reduce the VC induced by LRP1 via inhibiting the Wnt 5a signaling pathway. A PPAR $\gamma$ agonist could activate Wnt $5 \mathrm{a}$ signaling pathway antagonist sfrp2. $\beta$-catenin in canonical Wnt signaling pathways is encoded by the CTNNB1 gene. Certain researchers demonstrated that the mRNA levels of CTNNB1 were downregulated in adipocytes and murine adipose tissue following treatment with a PPAR $\gamma$ agonist, and $\beta$-catenin was also a transcriptionally targeted gene of PPAR $\gamma$ (29). All the above results suggested that the PPAR $\gamma$ agonist inhibited the expression of CTNNB1. Liu et al (30) confirmed that PPAR $\gamma$ and $\beta$-catenin exhibited a direct interactive effect. The authors suggested that PPAR $\gamma$ can suppress Wnt signaling pathways in normal cells by directing $\mathrm{p}-\beta$-catenin to the proteasome through a process involving its catenin binding domain. By contrast, oncogenic $\beta$-catenin resists proteasomal degradation by inhibiting PPAR $\gamma$ activity, which requires its TCF/binding domain. In the present study addition of $20 \mathrm{mM}$ PIO in the HP medium, resulted in the expression of $\beta$-catenin and cyclin D1 and the ratio of $\mathrm{p}-\mathrm{GSK}-3 \beta / \mathrm{GSK}-3 \beta$ all to be decreased. In addition, the present study also demonstrated that the effect of PIO on calcification and the Wnt/ $\beta$-catenin signaling pathway was reduced when adding the PPAR $\gamma$ antagonist GW9662. Therefore, it was inferred that PIO alleviated VC induced by HP levels, and its mechanism was through its activation of PPAR 
$\gamma$ and downregulation of the activation of the $\mathrm{Wnt} / \beta$-catenin signaling pathway.

In conclusion, the present study confirmed that PIO can suppress the calcification of VSMCs induced by HP via downregulation of the activation of the $\mathrm{Wnt} / \beta$-catenin signaling pathway. These results provided a novel strategy for the prevention and treatment of VC in CKD. The specific and detailed molecular mechanism of how PPAR $\gamma$ affected $\mathrm{Wnt} / \beta$-catenin signaling pathway remain unknown and requires further study in vivo.

\section{Acknowledgements}

The present study was funded by the Special Foundation for Clinical Science and Technology of Jiangsu Province (grant no. BL2014080), the Six Talent Peaks Project in Jiangsu Province (grant no. WSN-056) and the Priority Academic Program Development of Jiangsu Higher Education Institutions.

\section{References}

1. Shanahan CM, Crouthamel MH, Kapustin A and Giachelli CM: Arterial calcification in chronic kidney disease: Key roles for calcium and phosphate. Circ Res 109: 697-711, 2011.

2. Schlieper G, Schurgers L, Brandenburg V, Reutelingsperger C and Floege J. Vascular calcification in chronic kidney disease: An update. Nephrol Dial Transplant 31: 31-39, 2016.

3. Six I, Maizel J, Barreto FC, Rangrez AY, Dupont S, Slama M, Tribouilloy C, Choukroun G, Mazière JC, Bode-Boeger S, et al Effects of phosphate on vascular function under normal conditions and influence of the uraemic state. Cardiovasc Res 96 130-139, 2012.

4. Persy V and D'Haese P: Vascular calcification and bone disease: The calcification paradox. Trends Mol Med 15: 405-416, 2009.

5. Steitz SA, Speer MY, Curinga G, Yang HY, Haynes P, Aebersold R, Schinke T, Karsenty G and Giachelli CM: Smooth muscle cell phenotypic transition associated with calcification: Upregulation of Cbfal and downregulation of smooth muscle lineage markers. Circ Res 89: 1147-1154, 2001.

6. Giachelli CM: The emerging role of phosphate in vascular calcification. Kidney Int 75: 890-897, 2009.

7. Lanzer P, Boehm M, Sorribas V, Thiriet M, Janzen J, Zeller T, St Hilaire C and Shanahan C: Medial vascular calcification revisited: Review and perspectives. Eur Heart J 35: 1515-1525, 2014.

8. Brandenburg VM, Sinha S, Specht P and Ketteler M: Calcific uraemic arteriolopathy: A rare disease with a potentially high impact on chronic kidney disease-mineral and bone disorder. Pediatr Nephrol 29: 2289-2298, 2014.

9. Ivanova EA, Parolari A, Myasoedova V, Melnichenko AA, Bobryshev YV and Orekhov AN: Peroxisome proliferator-activated receptor (PPAR) gamma in cardiovascular disorders and cardiovascular surgery. J Cardiol 66: 271-278, 2015.

10. Wan Y: PPAR $\gamma$ in bone homeostasis. Trends Endocrinol Metab 21: 722-728, 2010.

11. Li F, Cai Z, Chen F, Shi X, Zhang Q, Chen S, Shi J, Wang DW and Dong N: Pioglitazone attenuates progression of aortic valve calcification via down-regulating receptor for advanced glycation end products. Basic Res Cardiol 107: 306, 2012.

12. Morena M, Jaussent I, Dupuy AM, Bargnoux AS, Kuster N, Chenine L, Leray-Moragues H, Klouche K, Vernhet H, Canaud B and Cristol JP: Osteoprotegerin and sclerostin in chronic kidney disease prior to dialysis: Potential partners in vascular calcifications. Nephrol Dial Transplant 30: 1345-1356, 2015.

13. Paloian NJ and Giachelli CM: A current understanding of vascular calcification in CKD. Am J Physiol Renal Physiol 307: F891-F900, 2014.

14. Yao L, Sun YT, Sun W, Xu TH, Ren C, Fan X, Sun L, Liu LL, Feng JM, Ma JF and Wang LN. High phosphorus level leads to aortic calcification via $\beta$-catenin in chronic kidney disease. Am J Nephrol 41: 28-36, 2015.
15. Speer MY, Yang HY, Brabb T, Leaf E, Look A, Lin WL, Frutkin A, Dichek D and Giachelli CM. Smooth muscle cells give rise to osteochondrogenic precursors and chondrocytes in calcifying arteries. Circ Res 104: 733-741, 2009.

16. EI'chaninov DV, Akker LV, Fedorova IA and Popovtseva AV: Bone resorption and formation markers in women with climacteric syndrome in early postmenopause. Klin Lab Diagn: 21-24, 2009 (In Russian).

17. Woldt E, Terrand J, Mlih M, Matz RL, Bruban V, Coudane F, Foppolo S, El Asmar Z, Chollet ME, Ninio E, et al: The nuclear hormone receptor PPAR $\gamma$ counteracts vascular calcification by inhibiting Wnt5a signalling in vascular smooth muscle cells. Nat Commun 3: 1077, 2012.

18. Zhou YB, Zhang J, Peng DQ, Chang JR, Cai Y, Yu YR, Jia MZ, Wu W, Guan YF, Tang CS and Qi YF: Peroxisome proliferator-activated receptor $\gamma$ ligands retard cultured vascular smooth muscle cells calcification induced by high glucose. Cell Biochem Biophys 66: 421-429, 2013.

19. Boyden LM, Mao J, Belsky J, Mitzner L, Farhi A, Mitnick MA, Wu D, Insogna K and Lifton RP: High bone density due to a mutation in LDL-receptor-related protein 5. N Engl J Med 346: 1513-1521, 2002.

20. Balemans W, Patel N, Ebeling M, Van Hul E, Wuyts W, Lacza C, Dioszegi M, Dikkers FG, Hildering P, Willems PJ, et al: Identification of a $52 \mathrm{~kb}$ deletion down-stream of the SOST gene in patients with van Buchem disease. J Med Genet 39: 91-97, 2002.

21. Bodine PV, Zhao W, Kharode YP, Bex FJ, Lambert AJ, Goad MB, Gaur T, Stein GS, Lian JB, Komm BS: The Wnt antagonist secreted frizzled-related protein-1 is a negative regulator of trabecular bone formation in adult mice. Mol Endocrinol 18: 1222-1237, 2004

22. Glass DA II, Bialek P, Ahn JD, Starbuck M, Patel MS, Clevers H, Taketo MM, Long F, McMahon AP, Lang RA and Karsenty G: Canonical Wnt signaling in differentiated osteoblasts controls osteoclast differentiation. Dev Cell 8: 751-764, 2005.

23. Holmen SL, Zylstra CR, Mukherjee A, Sigler RE, Faugere MC, Bouxsein ML, Deng L, Clemens TL and Williams BO: Essential role of beta-catenin in postnatal bone acquisition. J Biol Chem 280: 21162-21168, 2005.

24. Morvan F, Boulukos K, Clément-Lacroix P, Roman Roman S, Suc-Royer I, Vayssière B, Ammann P, Martin P, Pinho S, Pognonec P, et al: Deletion of a single allele of the Dkk1 gene leads to an increase in bone formation and bone mass. J Bone Miner Res 21: 934-945, 2006.

25. Li J, Sarosi I, Cattley RC, Pretorius J, Asuncion F, Grisanti M, Morony S, Adamu S, Geng Z, Qiu W, et al: Dkk1-mediated inhibition of Wnt signaling in bone results in osteopenia. Bone 39: 754-766, 2006.

26. Nakanishi T, Yamaai T, Asano M, Nawachi K, Suzuki M, Suqimoto T and Takiqawa M: Overexpression of connective tissue growth factor/hypertrophic chondrocyte-specific gene product 24 decreases bone density in adult mice and induces dwarfism. Biochem Biophys Res Commun 281: 678-681, 2001.

27. MacDonald BT, Tamai K and He X: Wnt/beta-catenin signaling: Components, mechanisms, and diseases. Dev Cell 17: 9-26, 2009.

28. Jansson EA, Are A, Greicius G, Kuo IC, Kelly D, Arulampalam V and Pettersson S: The Wnt/beta-catenin signaling pathway targets PPARgamma activity in colon cancer cells. Proc Natl Acad Sci USA 102: 1460-1465, 2005.

29. Guo F, Ren X, Dong Y, Hu X, Xu D, Zhou H, Meng F, Tian W and Zhao Y: Constitutive expression of PPAR $\gamma$ inhibits proliferation and migration of gastric cancer cells and down-regulates Wnt $/ \beta$-catenin signaling pathway downstream target genes TERT and ENAH. Gene 584: 31-37, 2016.

30. Liu J, Wang H, Zuo Y and Farmer SR: Functional interaction between peroxisome proliferator-activated receptor gamma and beta-catenin. Mol Cell Biol 26: 5827-5837, 2006. 